Article

\title{
A Shared Everyday Ethic of Public Sociability: Outdoor Public Ice Rinks as Spaces for Encounter
}

\author{
Mervyn Horgan *, Saara Liinamaa, Amanda Dakin, Sofia Meligrana and Meng Xu \\ Department of Sociology and Anthropology, University of Guelph, Guelph, N1G 2W1, Canada; \\ E-Mails: mhorgan@uoguelph.ca (M.H.), sliinamaa@uoguelph.ca (S.L.), adakin@uoguelph.ca (A.D.), \\ smeligra@uoguelph.ca (S.M.),mxu10@uoguelph.ca (M.X.)
}

* Corresponding author

Submitted: 9 July 2020 | Accepted: 1 September 2020 | Published: 12 November 2020

\begin{abstract}
Everyday life in urban public space means living amongst people unknown to one another. As part of the broader convivial turn within the study of everyday urban life (Wise \& Noble, 2016), this article examines outdoor public ice rinks as spaces for encounter between strangers. With data drawn from 100 hours of naturalistic and participant observation at free and accessible outdoor public non-hockey ice rinks in two Canadian cities, we show how 'rink life' is animated by a shared everyday ethic of public sociability, with strangers regularly engaging in fleeting moments of sociable interaction. At first glance, researching the outdoor public ice rink may seem frivolous, but in treating it seriously as a public space we find it to be threaded through with an ethos of interactional equality, reciprocal respect, and mutual support. We argue that the shared everyday ethic of public sociability that characterizes the rinks that we observed is a function of the (1) public and (2) personal materiality required for skating; (3) the emergence of on ice norms; (4) generalized trust amongst users; (5) ambiguities of socio-spatial differentiation by skill; and (6) flattened social hierarchies, or what we call the quotidian carnivalesque. Our data and analysis suggest that by drawing together different generations and levels of ability, this distinct public space facilitates social interactions between strangers, and so provides insights relevant to planners, policy makers and practitioners.
\end{abstract}

\section{Keywords}

affordances of sociability; conviviality; everyday ethics; public ice rinks; public space; strangers

Issue

This article is part of the issue "Built Environment, Ethics and Everyday Life" edited by Mattias Kärrholm (Lund University, Sweden) and Sandra Kopljar (Lund University, Sweden).

(C) 2020 by the authors; licensee Cogitatio (Lisbon, Portugal). This article is licensed under a Creative Commons Attribution 4.0 International License (CC BY).

\section{Introduction}

While an ethical worldview can inform public space design, the people who use public spaces and the interactions between them give life to everyday ethics. Ethics may inform design, but actual everyday use may not reflect those ethics: intentions and consequences are rarely one and the same thing.

Everyday life in urban public space means living amongst people unknown to one another (Amin, 2008; Horgan, 2012). While the existence of public space alone may not be a sufficient condition for creating a just and equal society, it is certainly a necessary one. Truly public spaces that are free and accessible, facilitating contact across various forms of social difference, are both necessary and desirable to any vision of a just and inclusive city (Cattell, Dines, Gesler, \& Curtis, 2008; Young, 1990).

Here we examine one type of temporally bounded, weather-dependent public space dedicated to recreational activity: outdoor municipally-managed public ice rinks where ice hockey is not permitted (hereafter, outdoor public ice rinks). These are a common recreational feature in many northern cities with winter temperatures consistently below freezing. While numerous free- 
form leisure pursuits-cycling, skateboarding, joggingcan take place within and across a wide variety of public spaces, ice-skating is necessarily temporally and spatially circumscribed; the rink is a specialized space in need of regular maintenance. Unlike some other pursuits requiring single-use facilities (e.g., golf, squash, tennis), recreational skating is not associated primarily with elites. As a form of public recreational activity, skating is potentially available to a wide population and has positive implications for both public health (Frumkin, 2003) and community identity (Francis, Giles-Corti, Wood, \& Knuiman, 2012 ) in cold climates. Rinks make possible public sociability that may be otherwise lacking in public spaces during winter months.

Drawing on 100 hours of systematic naturalistic and participant observation at outdoor public ice rinks in two Canadian cities, this article focuses on features of these outdoor public ice rinks that facilitate sociability. The specific type of ice rinks that we observed are free to access, centrally located and, importantly, where ice hockey is forbidden. Many Canadian towns and cities have municipally managed indoor and outdoor rink facilities, usually with a mixture of times for ice hockey and for recreational skating. Over half of Canada's 25 most populous cities offer free outdoor public ice rinks exclusively for recreational skating (that is, no hockey), with many located in city hall plazas (for example, in Calgary, Edmonton, Guelph, Kitchener-Waterloo, Ottawa, Regina, Toronto), or located downtown and/or close to other major municipal facilities (e.g., Halifax, Hamilton, London, Quebec City, St. John's, Vancouver, Windsor). This type of rink can be further distinguished from backyard and community rinks across Canada, as these too tend to be overwhelmingly dominated by ice hockey (Frederiksen, McLeman, \& Elcombe, 2018). Similar types of outdoor public rinks also exist in northern US cities (for example, New York City's Bryant Park and Chicago's Millennium Park) and in Northern European cities (for example, Stockholm's Kungsträdgården and Oslo's Spikersuppa rink).

While our empirical data is based exclusively on naturalistic and participant observation, our analysis is informed primarily by social scientific literature on urban sociability concerned with the possibilities and perils of everyday interactions between strangers in public space. We show how the built form of the rink and the social activity of skating are animated by a shared everyday ethic of sociability amongst rink users. We suggest that analyzing the social organization of the outdoor public ice rink deepens our understanding of how the design, management, promotion and use of such spaces can help planners and designers contribute to cultivating and sustaining soft infrastructures of sociability across various forms of social difference.

\section{Outdoor Public Ice Rinks and/as Public Spaces}

Interactions between strangers in the Anglo-North American public realm are underpinned by an ethic of civil inattention (Goffman, 1963), where strangers offer one another mutual indifference (Durkheim, 1964; Simmel, 1971). The rules are not hard and fast; some interactions are attentive - a friendly word, offers of assistancewhile others may be uncivil (Horgan, 2019, 2020; Smith, Phillips, \& King, 2010). Sociologists demonstrate multiple factors shaping interactions between strangers in public spaces, including, social characteristics like age (Cahill, 1987; Corcoran, Gray, \& Peillon, 2009), gender (Gardner, 1995; Lenton, Smith, Fox, \& Morra, 1999), and race (Anderson, 2011; Raudenbush, 2012). Also important are types of public space and associated activities (Goffman, 1963; Smith et al., 2010), and basic spatio-temporal features, such as time of day and seasonal weather conditions (Grazian, 2009; Milbrandt, 2020; Nash, 1981; Vannini, Waskul, Gottschalk, \& Ellis-Newstead, 2012; Zacharias, Stathopoulos, \& Wu, 2001).

Below, we first discuss existing literature on ice rinks, finding a dearth of research on outdoor public hockeyfree ice rinks. We then turn to social scientific literature on interactions between strangers in public spaces. This sets the scene for the data reporting and conceptual development that follows.

\subsection{Ice Rink Research}

Ice rinks figure strongly in the collective imaginations of northern countries. Popular images posit outdoor rinks as sites for romance and seasonal sociability, perhaps most famously in New York's Rockefeller Plaza. In Canada's national imaginaries, ice rinks are iconic, appearing in wide varieties of popular media representations of Canadian-ness (Cormack \& Cosgrave, 2013), but ice rinks are overwhelmingly associated with ice hockey. Ice hockey's status is near religious (Trothen, 2006): “[If] hockey is a Canadian religion, then the outdoor rink is the church" (Ramshaw \& Hinch, 2006, p. 404). Outdoor hockey rinks are widely romanticized within narratives of childhood and nationhood (Johnson \& Ali, 2017), with the 'mythologized space' of backyard rinks at the core of privatized forms of community building (Frederiksen et al., 2018, p. 47). Accordingly, both popular representations of outdoor rinks and rink research focus near exclusively on hockey.

Our interest here is not in advancing or undermining this iconicity or mythological status, rather, we complicate the picture, showing how outdoor hockey-free public rinks are qualitatively different. While hockey is interesting in its own right, existing research indicates its alignment with social exclusion. Evidence is mounting that ice hockey is increasingly a preserve of the wealthy (Mirtle, 2013), contributing to a broader problem of "physical activity culture that disproportionately favours organized, competitive sport" (Johnson \& Ali, 2017, p. 259). Relatedly, the public availability of rinks for non-hockey use generates local-level conflict in Canadian cities; one municipality developed separate indoor community rinks "to avoid conflicts among 
hockey players and family skaters" (Winder, 1998, p. 89). More recently, a Montreal scheme seeking to develop interest in hockey amongst immigrants and racialized groups built temporary outdoor rinks in communities with high numbers of immigrants and visible minorities. Researchers there noted that even in an ethnically heterogenous neighbourhood, rink users appeared to skew both white and male (Roult, Adjizian, Lefebvre, \& Lapierre, 2014). With recreational hockey dominated by relatively well-off white men, participation by wider publics is limited. Research on the culture of hockey has found the sport in general, whether professional or recreational, and hockey rinks in particular, to be highly-charged sites of racism, sexism, homophobia, and hegemonic masculinity (Allain, 2008; MacDonald, 2018; Robidoux, 2012; Robinson, 1998; Runstedtler, 2016; Theberge, 1998). Beyond hockey, ice skating has also received dedicated focus in existing literature, particularly figure skaters' personal aesthetic and embodied experiences (Adams, 2011; Maivorsdotter \& Wickman, 2011). Researchers have also positioned ice skating as serious leisure (McQuarrie \& Jackson, 1996; Stebbins, 2007).

Outdoor skating in public spaces barely appears in existing research (Mair, 2009). Studies of seasonal variability in public space usage refer to rinks only in passing, with little research focused exclusively on outdoor public ice rinks (Chen \& Ng, 2012; Li, 1994; Nash, 1981). Research attending to 'socialization' in outdoor rinks focuses on national identity and media representations, rather than empirical data from rinks themselves (Edwards \& Kulczycki, 2018, pp. 413-415). Yet, a UK-based study of temporary rinks found that:

[The] embodied pleasure of moving over ice, the sensorial pleasures of the cold, the festive socialities of the season and the visual pleasures of the spectacle of people skating, are intensely productive of an urban vitality that is popular, democratic and intensely sociable. (Bell, 2009, p. 15)

Generally, public rinks fit with the 'ludic city' as a space of unstructured play that modifies "relations between perceptions, intentions, actions and objects" (Stevens, 2007, p. 197).

Beyond these studies, outdoor public hockey-free rinks are underscrutinized as social environments in general, and as a space for sociability between strangers in particular. Hockey's dominance and associations with social exclusion may blinker understandings of rinks as more broadly sociable spaces. We use social scientific methods and data to address this oversight. Before turning to this, we first survey literature on interactions in public spaces more generally.

\subsection{Interactions in Public Spaces}

While the outdoor public ice rink as a site of sociability has been largely overlooked, social scientists treat public spaces as important sites for social contact across difference and for staking democratic claims (Mitchell, 2017). Surprisingly, despite both being concerned with public spaces, historically, there is little sustained dialogue and mutual influence between planning research on the design and management of the public realm and social scientific research on public interactions between strangers: Planners may seek to design spaces that facilitate stranger encounters, but what of the features of those interactions themselves? Urban design literature focused on material elements of public spaces is often underpinned at a macro level by democratic political philosophy, and concerned at an individual level with cognitive evaluations of design elements and personal safety (Amin, 2008; Del Aguila, Ghavampour, \& Vale, 2019; Mehta, 2009, 2014). Some recent work on urban design explicitly examines how topographical features of public spaces can facilitate encounters between strangers (Wang \& Stevens, 2020). For example, building on influential work on the public realm (Jacobs, 1961; Oldenburg, 1999), Simões-Aelbrecht (2010, p. 113) calls attention to the "spatial, social and experiential conditions...conducive to social interactions amongst strangers" (see also Simões-Aelbrecht, 2016).

Sociologists examine the social organization of public spaces, treating public spaces as settings for encounters between strangers (De Stefani \& Mondada, 2018; Goffman, 1963; Mondada, 2009; Smith, 2017; Wessendorf, 2013). The interactional organization of public spaces-the "urban interaction order" (Horgan, 2017, 2019)-requires the ongoing mutual accomplishment of order amongst co-present strangers. Interactionally-attuned sociologists emphasize the particularity of the interactional dynamics characterizing types of social contact between strangers in urban public spaces (Lofland, 1973; Morrill, Snow, \& White, 2005). Echoing Simmel's conception of the 'blasé attitude' (1971) as a necessary individual level adaptation to urban experience, and dovetailing with the concept of 'civil inattention' (Goffman, 1963, pp. 83-88) noted above, Lofland (1973, p. 151) refers to densely populated urban public space as a 'world of strangers' where urbanites develop a 'symbolic shield of privacy' particularly in instrumental spaces like public transit and on busy sidewalks.

Empirical research illustrates, though, that civil inattention is not universally applicable in public spaces (Gardner, 1995). Raudenbush (2012, p. 459), for example, shows its' uneven application in public settings where strangers are co-present, observing "racial differences in the use of civil inattention" on public transit in Chicago, observing that African-Americans generally uphold the norm of civil inattention only when white people are present, and that a more relaxed sociability occurs when only African-Americans are present. Connected to this, many scholars adopt the fearavoidance paradigm (Smith et al., 2010), treating individuals in cities as predominantly fearful of strangers, and in- 
teractions between strangers as fraught and/or perilous. Given this paradigm's dominance, much social scientific work on urban space focuses on 'disorder' (Sampson \& Raudenbush, 1999), treating urban spaces as characterized by mutual distrust. Focusing on observations and accounts of interactions between strangers, Duneier and Molotch (1999, p. 1276) outline the 'tacit conventions of sociability' that organize interactions between strangers in public spaces, while Anderson's (2011) 'cosmopolitan canopy' analyzes mundane encounters to delineate possibilities for civil sociability between strangers across racial differences.

In a similar spirit, Gilroy (2004, p. xi) draws attention to "the processes of cohabitation and interaction that have made multiculture an ordinary feature of social life." This observation has inspired a 'convivial turn' (Neal, Bennett, Cochrane, \& Mohan, 2013) in the social scientific study of the everyday spaces where stranger encounters take place. Contemporary convivialities researchers, primarily anthropologists, geographers and sociologists, examine actually existing interactions between strangers across various forms of social and cultural difference, especially in public settings and institutions, schools, markets, sidewalks, and public parks (Barker, Crawford, Booth, \& Churchill, 2019; Blommaert, 2014; Germain, 2013). This research demonstrates that while conflict does still appear (Anderson, 2011; Back \& Sinha, 2016), everyday interactions between strangers in public settings are not necessarily fraught and are often characterized by conviviality.

Having situated our study within literatures on ice rinks, public spaces and conviviality, next we outline our research methods, then we report descriptive data, before turning to an analysis of elements making up the shared everyday ethic of public sociability.

\section{Rinks as Social Spaces}

The present study of outdoor public ice rinks is part of a broader research program examining interactions between strangers in Canadian public spaces. Our wider project-the Sociable Cities Project-examines properties of public spaces and characteristics of encounters facilitating or mitigating against sociability between strangers. Our empirical research is underpinned by a normative commitment to the centrality of public spaces as key sites for encounters across difference in the context of an increasingly large, mobile, diverse, and unequal global urban population. We are especially interested in understanding the promises and perils of public spaces as realms for the production, maintenance and dissolution of everyday solidarity between strangers. Ice rinks are the first sites in this broader study (others include playgrounds, transit and parks). We treat rinks not simply as spaces where encounter is likely, but as public spaces that explicitly produce encounters between strangers - skating as an embodied physical activity is near impossible to do in public without engaging in some kind of social interaction. Moreover, as a leisure setting, it does so in a relatively low-stakes, generally non-instrumental way.

Before discussing our data, we will outline our methods. Between December 2019 and March 2020 (our observations were cut short in mid-March 2020 by the COVID-19 pandemic), we conducted naturalistic and participant observation at two outdoor public rinks in Canada, one in Guelph, a mid-size Canadian city, and the other in downtown Toronto, Canada's largest and most diverse city. Collectively, we observed for a total of 100 hours across 50 discrete observation periods ranging in duration from 0.5 to 3 hours, with an average of 1.25 hours, spreading observations across day of the week and time of day to capture potential temporal variations. Our team of five researchers (this article's co-authors) consists of female and male, immigrant and Canadian-born, visible minority and white, as well as both seasoned skaters and novices, and range in ages from early 20 s to early 40 s. Our various social differences and skill levels sensitized each of us to observing what other team members may not have noticed, thus collectively developing a broader and more nuanced set of observations.

Our naturalistic and participant observations followed standard sociological methods for the description and analysis of social settings, focusing in particular on observable features of the setting, actors and activities (Lofland \& Lofland, 1984; Spradley, 1980). To systematize our observations, every observation period began with each researcher recording time of day, weather, number and basic demographic characteristics of users that could be determined visually or aurally (for example, estimating age, gender, white/visible minority, skill level) through unobtrusive observation. Each of us then varied our time between skating and not skating, reasoning that the embodied experience of skating would bring us to observe interactions on ice more closely, and that observing from the margins would help make some more general observations about the rink as a whole. While we did not solicit interactions with other rink users, if someone initiated interaction we reciprocated. Interpersonal acknowledgments and spontaneous brief conversations amongst strangers were frequent. Across our observations, young children, caregivers, men, women, teenagers, elderly persons, and cognitively impaired persons initiated conversations with each one of us.

Throughout the observation phase, the research team shared field notes and met regularly, both inperson and virtually, to discuss our observations. Once the observation period was complete, we reviewed our individual observations, and collaboratively developed 'sensitizing concepts' (Blumer, 1954, pp. 7-9) to describe and analyze observations shared across multiple observers and observation periods. These form the basis of our analysis.

While there are some notable differences between our two field sites (size, relative density, availability of in- 
door space, immediate environs, etc.), our primary focus is on common features of the social organization of the rink. Particularly, we foreground elements of rink life that bear directly on the inter-relationships of built environment, ethics and everyday life via interactions between strangers. Needless to say, there are thousands of discrete observations that we could report but space does not permit us to itemize and describe these observations in toto. Consequently, our focus is necessarily narrower. Following a basic description of rink life, and based on an analysis of our observations, we concentrate on those specific elements of rink life relevant to the shared everyday ethic of public sociability.

\section{Rink Life: Some Basic Observations}

Our observations focus on a particular type of ice rinkmunicipally managed, urban rinks with well-developed facilities, regular ice maintenance, clearly stated safety guidelines, and accessibility features (e.g., sloped access points, accessible washrooms). The two rinks where we gathered data are both located in the central business districts of each city; they are centrepieces of municipal plazas containing each municipality's city hall. Neither rink charges an admission fee. By virtue of being free, accessible, centrally-located, hockey-free, and outdoors, the rinks we observed are distinct from other types of rink that previous researchers have examined. These rinks, though, are by no means unique: As noted, over half of Canada's 25 most populous cities have rinks of this type and location. These rinks are designed to accommodate those with mobility impairments, and with adaptations to facilitate assistive devices; however, sports equipment, like hockey sticks and pucks are not allowed. Many other free community outdoor rinks do not have these sorts of formalized guidelines and facilities, and such rinks tend to be hockey dominated.

Though the precise times and dates of opening and closing of both rinks are weather dependent, in winter months (late November to late March/early April) they are generally open daily for more than 12 hours. Both rinks have seating around the perimeter, this faces towards the rink providing a place for skaters to rest and spectators to watch. Immediately adjacent to the Guelph rink there is a small heated glass-walled changing room and locker facility that includes two public washrooms, and a nearby store offers reasonably-priced skate rentals. The Toronto rink has a locker facility and a dedicated skate rental counter. The Toronto rink has a rink monitor on duty at all times, while the Guelph rink did not always have a visible official presence, though municipal workers were sometimes present.

The number of users on the ice at any given time ranged from zero to well over one hundred with equivalent numbers present in the rinks' immediate environs. When large numbers are present, the constant to and fro between skating and resting made precise numbers at any one point in time difficult to determine. In general, far fewer skaters were present on days where the temperature approached or dipped below minus 20 degrees Celsius. Weekday mornings at both locations tended to be quiet, with a notable uptick in numbers of users on milder evenings and a huge swell in numbers on weekends and holidays, with weekend and holiday afternoons consistently the busiest at both rinks.

Skaters ranged in age from two years old to over 70 . Children under 12 and accompanying adults tended to be the most frequently occurring group at both rinks. We also commonly observed groups of teenagers, and adults in singles and pairs. Both opposite and same-sex couples from teenagers to older adults over 60 were also regular users, with younger couples tending to skate together side-by-side for longer periods than older ones. Unaccompanied skaters at both rinks tended to be adult men, predominantly white at the Guelph rink but more visibly diverse in Toronto. A mix of novices and experienced skaters were present in every observation period where at least five skaters were present. Child learners were generally under 10 and visibly diverse, while adult learners at both rinks tended to be visible minorities and/or non-native English speakers. The Toronto rink was always ethnically diverse, while Guelph rink users tended to be predominantly, though by no means exclusively, white. Larger groups of five to ten teenagers and young adults appeared frequently at both rinks, and these groups were often ethnically mixed with very varied skill levels. In Guelph most skaters communicated in English, but we also heard French, German, Japanese, Polish, and Tagalog, while in Toronto many different languages were in use throughout each observation period.

Again, while we could catalogue thousands of discrete observations from both sites, having provided a basic description of rink life, we now turn to a more focused discussion and analysis of the social organization of the rink.

\section{A Shared Everyday Ethic of Public Sociability: Affordances of Sociability at the Rink}

In this section we draw upon our observational data to demonstrate how outdoor public ice rinks are characterized by a shared everyday ethic of public sociability. We define this ethic as a mutual orientation in mundane social interaction in public space, where strangers freely and fleetingly interact without visibly evident instrumental reasons for doing so. Below we draw upon data from our naturalistic and participant observations to demonstrate how this ethic is informally produced and upheld by rink users. We propose that the emergence and sustenance of this ethic derives from affordances of sociability, that we define broadly as any elements of a social setting that facilitate positive interactions between strangers. Settings with numerous and varied affordances of sociability form an essential part of what we call soft infrastructures of sociability. In the present study, we locate these affordances in the material and 
social organization of the outdoor public ice rink (see also Rietveld \& Kiverstein, 2014). Specifically, we note the following features that are salient at the rink. The requirements of skating as a specific type of physical activity provides affordances of sociability through (1) public materiality, which refers to the built environment of the rink and its environs, and (2) personal materiality, which refers to the specialized equipment necessary for skating. Further, the social organization of the rink as a space for expressive activity provides affordances of sociability through; (3) norm emergence that is reasonably consistent in the relative absence of explicit sanctions or overarching intervening authorities; (4) generalized trust amongst users; (5) ambiguities of socio-spatial differentiation by skill; and (6) a quotidian carnivalesque, whereby social hierarchies are generally flattened and sometimes inverted due to the temporarily diminished salience of non-rink status hierarchies. Each of these elements is discussed in detail below. Throughout, we provide illustrative examples from our field notes. Important to note here is that the six elements that we delineate are not wholly discrete and distinct from one another. We parse them out here for the purposes of description, analysis and illustration; in practice, in our observations we found them to be imbricated with one another. As social scientists we analytically disentangle constitutive elements while recognizing that they are more fully integrated in the everyday realities of rink life. We conclude this section with a discussion of some limits to our study.

\subsection{Public Materiality}

Specific elements of the skating rink as a built environment enable sociability between rink users. Most obviously, the existence of the rink itself provides a shared space for engaging in a seasonal leisure activity, an especially important one since winter weather tends to curtail outdoor activities in public spaces. While our data is exclusively observational and does not yet include interviews, we can assume that people who come to use the rink come in the knowledge that it is a shared space, and one that they take pleasure in using. As a free and open public space, users come expecting to share it with unknown others.

One especially significant feature of the rink as a built environment is the open bench seating around the perimeter. On every occasion where children and caregivers were present, we observed caregivers call out to children from this seating or vice versa. The shared nature of the seating itself affords sociability as it makes side conversations with proximate others possible. We regularly observed parents and caregivers engaging in friendly exchanges with one another, and they often shared knowing glances when younger children were having tantrums. For example, from our field notes:

It's a busy Sunday afternoon... with about 35 people present, about 20 of them are children....A young white boy, around 5 or 6 appears quite upset, but it's not clear why. Immediately after his caregiver comforts him, another caregiver at the bench to her right smiles and exchanges words as they both watch him race back on to the ice.

Adults regularly offered encouragement to children unknown to them from the sidelines. Adults who are strangers to one other may comment on the skill of a young child or offer pointers to novices. Again, from our field notes:

A young girl, around 4 or 5 , keeps trying to skate ahead of her caregivers, but has difficulty keeping her balance....She falls for the 5th or 6th time immediately in front of a middle aged white man taking a rest on a bench who catches her eye and says: "Keep bending those knees, you're doing a great job!"

Benches of this sort are a valuable resource because they are "public, egalitarian and free.....and allow people to loosely belong within the flow of city life" (Bynon \& Rishbeth, 2015, p. 3).

\subsection{Personal Materiality}

Skating requires not only a public rink, but also personal materials, including skates, a helmet (mandatory for children at both rinks), and warm winter clothing. While there is a cost associated with the necessary equipment, the trade in second-hand and hand-me-down skating and winter gear in Canada is both widespread and relatively inexpensive. A young child can be kitted out with basic skates and a helmet for the equivalent of 3-4 hours minimum wage work. In addition to thrift stores, a wellestablished network of second-hand sports stores also accept trade-ins, so as children grow out of skates and helmets these can be traded in for store credit, and so after the initial investment, future costs can be lowered. Worth noting here is that the price tag for participation in ice hockey is substantially higher and prohibitive for many (Mirtle, 2013) because much more and specialized equipment is involved, to say nothing of coaching, competition and 'ice-time' costs.

The skating boot itself often afforded sociable interactions. The strangeness of skates for the uninitiated were a constant source of interaction between strangers. We observed eight occasions where seasoned skaters advised novices having difficulty squeezing into new or rented skates, for example, with strangers offering advice like: "You gotta loosen the laces all the way down the skate," and, "if you stand up you'll slip into it more easily." Additionally, if they were far from their caregiver, we witnessed small children on the ice ask random nearby adults to help with undone laces on six occasions. A familiar sound from adults at a rink is a sigh of relief as laces are opened and skates removed. These sighs were often commented on by nearby adults. We overheard com- 
ments such as "isn't that the best feeling in the world?!" and "that is the best part of skating."

Winter wear in general also leads to sociable encounters. In North American society 'territories of the self' (Goffman, 1971)-including one's body, personal possessions and personal space-are sacrosanct, and in most public contexts, inviolable, with demonstrable offence generally taken when these territories are violated by strangers in particular. At the rink, territories of the self are blurred. For example, it's not unusual for skating children and young adults to cast their winter jackets aside when they get too hot, with little concern for where they land (young boys, in particular, appear to take great pride in skating in t-shirts). These expanded territories of the self necessarily overlapped with those of others, as strangers' clothing piled up, with some searching for shoes beneath piles of others' clothing. In our 100 hours of observation, we did not once witness this leading to any kind of overt conflict.

\subsection{Emergent Norms}

Both rinks had some signage indicating rules/etiquette for users, but the rink surface appears to be largely selforganized through implicit agreement amongst skaters. Direction of flow is a good example: Agreement about direction of travel is arrived at collectively without explicit communication. When small numbers are present, skating is multi-directional, but once a critical mass is reached (generally, about seven or eight people) a unidirectional flow emerges (at the larger rink, attendants intervened if someone consistently skated in the wrong direction). For example, during an early evening weekday observation, only four skaters were present, some skating clockwise, another counterclockwise, and one in the rink's centre skating back and forth in a straight line. As more people arrived, seemingly naturally, everyone began skating in the same direction. As it involves a demonstrable mutual orientation and commitment (Rawls, 1990) between skaters, we call this an 'emergent norm.'

Those who do engage in counter flow are generally those providing assistance to fallen or struggling skaters, and children, mostly pre-teen/teenage boys. On every occasion where at least three pre-teen/teenage boys were present we observed them skating very quickly, stopping abruptly, performing tricks (such as skating backwards), skating in inconsistent directions, and being louder than other users. While their caregivers sometimes called out to these boys to be more careful, we never once observed other skaters treating this as disruptive or making facial or audible gestures that outwardly demonstrated upset.

What is especially interesting about this emergent norm is that unlike other public settings, breaches of the norm do not seem to draw immediate sanction from other users (Goffman, 1963, 1971). Rather, disruptions tend to be fleeting and quickly reabsorbed.

\subsection{Generalized Trust}

In addition to norm emergence above, users at the smaller rink in particular, appeared to demonstrate a high degree of trust, unguarded personal possessions being a clear example. During busy weekend periods, we observed many people leaving personal belongings on top of and underneath the outdoor benches, and skaters rarely stopped to check on their belongings. This is especially noteworthy since both rinks have secure locker facilities that few skaters use.

This atmosphere of generalized trust is not only with regard to personal possessions. It is especially evident in caregiver-child relationships. For example, almost all small children with some skating competence skated far from their caregivers, at distances much greater than commonly observed in other public spaces. Accompanied children appear to be less subject to direct supervision than at public playgrounds, for example. Attesting to the implicit trust characteristic of these rinks, most strikingly, we twice observed young children (under 10) skating alone while caregivers ate at restaurants visible from the rink. While there is much research to show that children perceive public spaces as potentially dangerous, and that both they and their parents generally act in line with this belief (Cahill, 1990; Harden, 2000; Valentine, 1996, 1997), the rink appears to be a space where such fears are fleetingly suspended, and where children can express and enact some degree of autonomy.

\subsection{Ambiguities of Socio-Spatial Differentiation by Skill}

While the physical surface of the rink is largely undifferentiated, observations suggest some differentiation by skating skill. By virtue of the type of movement involved, skaters weave to avoid one another, with steady skaters, leaving space (anywhere from 1-3 feet, depending on density) between them when passing. Skilled skaters can easily avoid more hesitant novices, and novices quickly learn not to fear high-speed skilled skaters. Beginning skaters tend to shuffle around the very outer edge of the ice, sometimes holding onto someone without skates who walks around holding them, other times to a more skilled or fellow-learner friend. Occasionally, beginners try to find their balance at the very centre of the rink, though getting there often proves difficult. We twice witnessed wheelchair users wheel onto the ice, moving from the perimeter to the centre and interacting with skaters. Highly skilled skaters as well as learners use the outer edge, and this very mixing of skill levels lends itself to encouraging words, sharing of advice, and, often, direct physical assistance. These patterns though are not fixed; on one weekend afternoon as we observed the rink become increasingly dominated by families with young children who skated on the outside of the rink. Consequently, stronger skaters moved towards the center. 
No single group or skill-level dominates the ice rink. That said, in general, showy displays of skating prowess (e.g., skating backwards, 'hockey stops,' fast turns), tended to be from competent male skaters from the very young to the middle-aged, often wearing the jersey of an ice hockey team. Only twice did we witness flamboyant figure skating maneuvers - in both cases, by women-in the centre of the ice in the immediate presence of novices. Like activities in public spaces more generally, activities on ice are gendered. That said, activities on the rinks we observed did not appear subject to the kinds of gendered performances that so clearly dominate on hockey rinks. The ambiguities of socio-spatial differentiation by skill, where novices and seasoned skaters share space and with no one group controlling or dictating parts of the ice surface or the surface as a whole, appears to facilitate a collaborative and somewhat egalitarian ethos on the ice.

\subsection{Quotidian Carnivalesque}

Building on the ambiguities of socio-spatial differentiation by skill, the rink provides a space where the mixing of, in particular, skill levels, genders and ages, disrupts status hierarchies that may be salient outside the rink. We call this the quotidian carnivalesque. For Bakhtin (1984a, 1984b), the carnivalesque refers to occasions where social hierarchies may be flattened, disrupted and inverted.

In over half of our observation periods, young children not only outnumbered adults, but appeared more skilled than many adults present. The mixing of skilled children and relatively hapless adults inverts pervasive age-based status hierarchies. For example, early on a weekend evening, a man skating at high speed fell spectacularly. A toddler skated towards him, reaching out to help him up. The toddler's father skated over, moved the toddler aside and helped the man up. After a few friendly words, all returned to skating. The embarrassment one might expect is tempered substantially on the ice, as failure is frequent, more or less routinized, and treated frivolously. Indeed, failing became a source of fun, with those who fall usually laughing at themselves, and nearby strangers sharing a smile once they determined that the faller was not injured.

Across 100 hours of observation we witnessed dozens of falls, though no serious injury evidently occurred. Strangers regularly assisted in picking up fallen skaters, checking 'are you ok?' Stumbling skaters (including our research team), regularly experienced a steadying-hand on their backs or shoulders as more skilled passing skaters-child or adult-sensed (usually correctly) impending falls. We witnessed female skaters assisting males and vice versa with no perceptible difference. Occasionally someone skates too close or if a nearby skater looks like they are about to fall, it is not unusual for another skater to reach out-regardless of age or gender-to physically support or gently push another skater.
We point to these instances as in Anglo-North American society, direct physical contact between children and adults who are strangers to them has the character of a taboo. Yet at the rink, this kind of reaching out-literal forms of support, whether from adult to child or vice versa-is thoroughly normalized. Prevailing hierarchies of gender and age, and the usual touching rules between strangers in public spaces appear to be modulated when on ice. While this does not make the rink a carnival, the suspension of hierarchies does give it a carnivalesque quality in the Bakhtinian sense, especially when busy.

\section{Summary and Limits}

The rink as a public space and skating as a public activity provide affordances of sociability that yield social interactions between strangers beyond the civil inattention characteristic of North American urban spaces. Derived from our observational data, the six elements described above characterize a shared everyday ethic of public sociability at the outdoor public ice rink. This ethic is informally produced and upheld by rink users. We distinguish these six elements analytically, though in practice they are less distinct. We suggest that rink life appears to suspend many of the fears, norms and hierarchies that, as discussed in our literature review, researchers have found both on ice hockey rinks and in public spaces.

While sociability between strangers was evident in every observation period and the picture we paint above is largely positive, not all observed interactions were uniformly sociable. We do not wish to claim that outdoor public ice rinks are some sort of panacea, free from social exclusion. We note in particular that the presence of official rink monitors in Toronto rink led on two separate occasions to street-involved persons not wearing skates being asked to leave the rink surface. We also witnessed rink monitors shouting at skaters who did not leave the ice as the ice-resurfacing machine (Zamboni) prepared to enter the rink. In addition, while the rink appears to offer some autonomy to children, the dominance of boisterous play amongst young boys dovetails with gendered socialization that treats public space as a primarily masculine domain (Gardner, 1995; Kern, 2019). While outdoor public ice rinks may not be free of the norms of hegemonic masculinity so prevalent at the hockey rink, these norms do appear to be tempered somewhat.

Some evident drawbacks of our study derive from the limitations of our method. While generative in its own right, research based exclusively on data gathered through naturalistic and participant observation from a five-person team does not necessarily capture all ways that users experience rinks. One-on-one interviews and surveys may generate different kinds of findings, in particular around personal perceptions about outdoor public ice rinks. Such data would help to deepen our understanding of varieties of experiences in this type of public space. 


\section{Conclusion}

While the sustained study of the outdoor public rink might seem inconsequential, its very everydayness veils the extent to which it is instructive for deepening understanding of public spaces as sites where strangers interact. Public ought to mean free and accessible to all, with minimal physical and financial barriers to entry. Rinks can offer important lessons for learning how we might make good on the inclusive principles of truly public spaces.

We have demonstrated how the endogenous organization of the rink by co-present persons generates and expresses a shared everyday ethic of public sociability. The rink is a space that affords interaction betweenand perhaps also openness to-strangers. It is animated by a mutual responsibility not only for maintaining some semblance of orderliness and trust, but also for pleasurable play through a demonstrably shared commitment to the collective production of fun. We hope that academics, urban planners, policy makers and community organizations-all those interested in how the relationship between the built environment and the ethics of everyday life manifests in the social life of the public realm-can draw on insights from the shared everyday ethic of sociability at the rink. By better identifying and cultivating soft infrastructures of sociability, we can collectively advance the social life of urban public spaces in our increasingly dense and diverse cities.

\section{Acknowledgments}

The authors would like to thank the Academic Editors, Mattias Kärrholm and Sandra Kopljar, and the two anonymous reviewers for their input. Thanks also to Mariana Pires and Tiago Cardoso for their assistance. The research for this article was conducted as part of the Sociable Cities Project funded by an Insight Grant (\#435-2018-0730) from the Social Sciences and Humanities Research Council awarded to Mervyn Horgan and Saara Liinamaa.

\section{Conflict of Interests}

The authors declare no conflict of interests.

\section{References}

Adams, M. L. (2011). Artistic impressions: Figure skating, masculinity, and the limits of sport. Toronto: University of Toronto Press.

Allain, K. A. (2008). 'Real fast and tough': The construction of Canadian hockey masculinity. Sociology of Sport Journal, 25(4), 462-481. https://doi.org/ $10.1123 /$ ssj.25.4.462

Amin, A. (2008). Collective culture and urban public space. City, 12, 5-24.

Anderson, E. (2011). The cosmopolitan canopy. New York, NY: Norton.
Back, L., \& Sinha, S. (2016). Multicultural conviviality in the midst of racism's ruins. Journal of Intercultural Studies, 37(5), 517-532. https://doi.org/ 10.1080/07256868.2016.1211625

Bakhtin, M. (1984a). Problems of Dostoevsky's poetics. Minneapolis, MN: University of Minnesota Press.

Bakhtin, M. (1984b). Rabelais and his world. Bloomington, IN: Indiana University Press.

Barker, A., Crawford, A., Booth, N., \& Churchill, D. (2019). Everyday encounters with difference in urban parks. International Journal of Law in Context, 15(4), 495-514. https://doi.org/10.1017/S1744552319000 387

Bell, D. (2009). Winter wonderlands: Public outdoor ice rinks, entrepreneurial display and festive socialities in UK cities. Leisure Studies, 28(1), 3-18. https://doi. org/10.1080/02614360802260952

Blommaert, J. (2014). Infrastructures of superdiversity. European Journal of Cultural Studies, 17(4), 431-451. https://doi.org/10.1177/1367549413510421

Blumer, H. (1954). What is wrong with social theory? American Sociological Review, 19(1), 3-10. https:// doi.org/10.2307/2088165

Bynon, R., \& Rishbeth, C. (2015). Benches for everyone: Solitude in public, sociability for free. London: The Young Foundation.

Cahill, S. (1987). Children and civility: Ceremonial deviance and the acquisition of ritual competence. Social Psychology Quarterly, 50(4), 312-321. https:// doi.org/10.2307/2786816

Cahill, S. (1990). Childhood and public life: Reaffirming biographical divisions. Social Problems, 37(3), 390-402.

Cattell, V., Dines, N., Gesler, W., \& Curtis, S. (2008). Mingling, observing, and lingering: Everyday public spaces and their implications for well-being and social relations. Health and Place, 14(3), 544-561. https://doi.org/10.1016/j.healthplace.2007.10.007

Chen, L., \& Ng, E. (2012). Outdoor thermal comfort and outdoor activities: A review of research in the past decade. Cities, 29(2), 118-125. https://doi.org/ 10.1016/j.cities.2011.08.006

Corcoran, M. P., Gray, J., \& Peillon, M. (2009). Making space for sociability: How children animate the public realm in suburbia. Nature and Culture, 4(1), 35-56. https://doi.org/10.3167/nc.2009.040103

Cormack, P., \& Cosgrave, J. F. (2013). Desiring Canada: $C B C$ contests, hockey violence and other stately pleasures. Toronto: University of Toronto Press.

De Stefani, E., \& Mondada, L. (2018). Encounters in public space. Research on Language and Social Interaction, 51(3), 248-270.

Del Aguila, M., Ghavampour, E., \& Vale, B. (2019). Theory of place in public space. Urban Planning, 4(2), 249-259. https://doi.org/10.17645/up.v4i2.1978

Duneier, M., \& Molotch, H. (1999). Talking city trouble: Interactional vandalism, social inequality, and the "urban interaction problem." American Journal of Sociology, 104(5), 1263-1295. 
Durkheim, E. (1964). The division of labour in society. New York, NY: Free Press.

Edwards, J., \& Kulczycki, C. (2018). 'Who wants to go the outdoor rink?': A media analysis of Canada's outdoor rinks. Leisure/Loisir, 42(4), 389-424. https://doi.org/ 10.1080/14927713.2019.1581990

Francis, J., Giles-Corti, B., Wood, L., \& Knuiman, M. (2012). Creating sense of community: The role of public space. Journal of Environmental Psychology, 32(4), 401-409. https://doi.org/10.1016/j.jenvp. 2012.07.002

Frederiksen, A., McLeman, R. A., \& Elcombe, T. L. (2018). Building backyard ice rinks in Canada: An exploratory study. Leisure/Loisir, 42(1), 47-68. https://doi.org/ $10.1080 / 14927713.2017 .1411822$

Frumkin, H. (2003). Healthy places. American Journal of Public Health, 93(9), 1451-1456. https://doi.org/ 10.2105/AJPH.93.9.1451

Gardner, C. B. (1995). Passing by: Gender and public harassment. Berkeley, CA: University of California Press.

Germain, A. (2013). The Montréal School: Urban social mix in a reflexive city. Anthropologica, 55(1), 29-39.

Gilroy, P. (2004). After empire: Melancholia or convivial culture? London: Routledge.

Goffman, E. (1963). Behavior in public places. New York, NY: Free Press.

Goffman, E. (1971). Relations in public. New York, NY: Harper Row.

Grazian, D. (2009). Urban nightlife, social capital, and the public life of cities. Sociological Forum, 24(4), 908-917. https://doi.org/10.1111/j.15737861.2009.01143.x

Harden, J. (2000). There's no place like home: The public/private distinction in children's theorizing of risk and safety. Childhood, 7(1), 43-59. https://doi.org/ 10.1177/0907568200007001005

Horgan, M. (2012). Strangers and strangership. Journal of Intercultural Studies, 33(6), 607-622. https://doi. org/10.1080/07256868.2012.735110

Horgan, M. (2017). Mundane mutualities: Solidarity and strangership in everyday urban life. In S. Oosterlynck, N. Schuermans, \& M. Loopmans (Eds.), Place, diversity and solidarity (pp. 19-32). Abingdon: Routledge.

Horgan, M. (2019). Everyday incivility and the urban interaction order: Theorizing moral affordances in ritualized interaction. Journal of Language Aggression and Conflict, 7(1), 32-55. https://doi.org/10.1075/ jlac.00018.hor

Horgan, M. (2020). Urban interaction ritual: Strangership, Civil inattention and everyday incivilities in public space. Pragmatics, 30(1), 116-141. https://doi. org/10.1075/prag.19022.hor

Jacobs, J. (1961). The death and life of great American cities. New York, NY: Vintage Books.

Johnson, J., \& Ali, A. E. (2017). Skating on thin ice? An interrogation of Canada's melting pastime. World Leisure Journal, 59(4), 259-271. https://doi.org/ $10.1080 / 16078055.2016 .1216889$
Kern, L. (2019). Feminist city. Toronto: Between the Lines. Lenton, R., Smith, M., Fox, J., \& Morra, N. (1999). Sexual harassment in public places: Experiences of Canadian women. Canadian Review of Sociology, 36(4), 517-540.

Li, S. (1994). Users' behaviour of small urban spaces in winter and marginal seasons. Architecture and Behaviour, 10(1), 95-109.

Lofland, J., \& Lofland, L. (1984). Analyzing social settings. Belmont, CA: Wadsworth.

Lofland, L. (1973). A world of strangers: Order and action in urban public space. New York, NY: Basic Books.

MacDonald, C. A. (2018). Insert name of openly gay hockey player here: Attitudes towards homosexuality among Canadian male major midget AAA ice hockey players. Sociology of Sport Journal, 35(4), 347-357. https://doi.org/10.1123/ssj.2017-0133

Mair, H. (2009). Club life: Third place and shared leisure in rural Canada. Leisure Sciences, 31(5), 450-465.

Maivorsdotter, N., \& Wickman, P. O. (2011). Skating in a life context. Sport, Education and Society, 16(5), 613-628. https://doi.org/10.1080/13573322. 2011.601141

McQuarrie, F., \& Jackson, E. L. (1996). Connections between negotiation of leisure constraints and serious leisure: An exploratory study of adult amateur ice skaters. Loisir et Société/Society and Leisure, 19(2), 459-483. https://doi.org/10.1080/07053436. 1996.10715528

Mehta, V. (2009). Look closely and you will see, listen carefully and you will hear: Urban design and social interaction on streets. Journal of Urban Design, 14(1), 29-64. https://doi.org/10.1080/ 13574800802452658

Mehta, V. (2014). Evaluating public space. Journal of Urban Design, 19(1), 53-88. https://doi.org/10.1080/ 13574809.2013 .854698

Milbrandt, T. (2020). Season of dreaded joys: Adaptation, enchantment, and solidarity in a 'Winter' city. In T. Davidson \& O. Park (Eds.), Seasonal sociology (pp. 119-138). Toronto: University of Toronto Press.

Mirtle, J. (2013, November 8). The great offside: How Canadian hockey is becoming a game strictly for the rich. The Globe and Mail. Retrieved from https://www.theglobeandmail.com/news/national/ time-to-lead/the-great-offside-how-canadianhockey-is-becoming-a-game-strictly-for-the-rich/ article15349723

Mitchell, D. (2017). People's park again: On the end and ends of public space. Environment and Planning $A$, 49(3), 503-518.

Morrill, C., Snow, D., \& White, C. (Eds.). (2005). Together alone: Personal relationships in public places. Berkeley, CA: University of California Press.

Mondada, L. (2009). Emergent focused interactions in public places. Journal of Pragmatics, 41(10), 1977-1997. https://doi.org/10.1016/j.pragma.2008. 09.019 
Nash, J. E. (1981). Relations in frozen places: Observations on winter public order. Qualitative Sociology, 4(3), 229-243.

Neal, S., Bennett, K., Cochrane, A., \& Mohan, G. (2013). Living multiculture: Understanding the new spatial and social relations of ethnicity and multiculture in England. Environment and Planning C: Government and Policy, 31(2), 308-323. https://doi.org/10.1068/ c11263r

Oldenburg, R. (1999). The great good place. New York, NY: Marlowe.

Ramshaw, G., \& Hinch, T. (2006). Place identity and sport tourism: The case of the heritage classic ice hockey event. Current Issues in Tourism, 9(4/5), 399-418.

Raudenbush, D. T. (2012). Race and interactions on public transportation. Symbolic Interaction, 35(4), 456-473. https://doi.org/10.1002/symb.36

Rawls, A. W. (1990). Emergent sociality: A dialectic of commitment and order. Symbolic Interaction, 13(1), 63-82. https://doi.org/10.1525/si.1990.13.1.63

Rietveld, E., \& Kiverstein, J. (2014). A rich landscape of affordances. Ecological Psychology, 26(4), 325-52. https://doi.org/10.1080/10407413.2014.958035

Robidoux, M. A. (2012). Stickhandling through the margins: First nations hockey in Canada. Toronto: University of Toronto Press.

Robinson, L. (1998). Crossing the line: Violence and sexual assault in Canada's national sport. Toronto: McClelland and Stewart.

Roult, R., Adjizian, J. M., Lefebvre, S., \& Lapierre, L. (2014). The mobilizing effects and health benefits of proximity sport facilities: Urban and environmental analysis of the Bleu, Blanc, Bouge project and Montreal North's outdoor rink. Sport in Society, 17(1), 68-88. https://doi.org/10.1080/17430437.2013.828698

Runstedtler, T. (2016). From white wash to black ice: Black athletes in unexpected places. Journal of American Ethnic History, 35(2), 79-90. https://doi.org/ 10.5406/jamerethnhist.35.2.0079

Sampson, R. J., \& Raudenbush, S. W. (1999). Systematic social observation of public spaces. American Journal of Sociology, 105(3), 603-651. https://doi.org/ $10.1086 / 210356$

Simmel, G. (1971). On individuality and social forms. Chicago, IL: University of Chicago Press.

Simões-Aelbrecht, P. (2010). Rethinking urban design for a changing public life. Journal of Place Management and Development, 3(2), 113-129. https://doi.org/ $10.1108 / 17538331011062667$

Simões-Aelbrecht, P. (2016). 'Fourth places': The contemporary public settings for informal social interaction among strangers. Journal of Urban Design, 21(1), 124-152. https://doi.org/10.1080/13574809. 2015.1106920

Smith, P., Phillips, T. L., \& King, R. D. (2010). Incivility: The rude stranger in everyday life. Cambridge: Cambridge University Press.

Smith, R. J. (2017). The practical organisation of space, interaction, and communication in and as the work of crossing a shared space intersection. Sociologica, 2, 1-32. https://doi.org/10.2383/88200

Spradley, J. P. (1980). Participant observation. New York, NY: Holt, Rinehart and Winston.

Stebbins, R. A. (2007). Serious leisure: A perspective for our time. New Brunswick: Transaction Publishers.

Stevens, Q. (2007). The ludic city: Exploring the potential of public spaces. London: Routledge.

Theberge, N. (1998). 'Same sport, different gender': A consideration of binary gender logic and the sport continuum in the case of ice hockey. Journal of Sport and Social Issues, 22(2), 183-198. https://doi.org/ $10.1177 / 019372398022002005$

Trothen, T. J. (2006). Hockey: A divine sport? Canada's national sport in relation to embodiment, community and hope. Studies in Religion/Sciences Religieuses, 35(2), 291-305. https://doi.org/10.1177/ 000842980603500206

Valentine, G. (1996). Children should be seen and not heard: The production and transgression of adults' public space. Urban Geography, 17(3), 205-220.

Valentine, G. (1997). 'Oh yes I can, oh no you can't': Children and parents' understandings of kids' competence to negotiate public space safely. Antipode, 29(1), 65-89.

Vannini, P., Waskul, D., Gottschalk, S., \& Ellis-Newstead, T. (2012). Making sense of the weather: Dwelling and weathering on Canada's rain coast. Space and Culture, 15(4), 361-380. https://doi.org/10.1177/ 1206331211412269

Wang, Z., \& Stevens, Q. (2020). How do open space characteristics influence open space use? Urban Research and Practice, 13(1), 22-44. https://doi.org/10.1080/ 17535069.2018.1484152

Wessendorf, S. (2013). Commonplace diversity and the 'ethos of mixing.' Identities, 20(4), 407-422. https:// doi.org/10.1080/1070289X.2013.822374

Winder, G. M. (1998). Neighbourhood community centres and the changing leisure culture in Brandon. The Canadian Geographer/Le Géographe Canadien, 42(1), 86-93. https://doi.org/10.1111/j.1541-0064. 1998.tb01555.x

Wise, A., \& Noble, G. (2016). Convivialities: An orientation. Journal of Intercultural Studies, 37(5), 423-431. https://doi.org/10.1080/07256868.2016.1213786

Young, I. M. (1990). Justice and the politics of difference. Princeton, NJ: Princeton University Press.

Zacharias, J., Stathopoulos, T., \& Wu, H. (2001). Microclimate and downtown open space activity. Environment and Behavior, 33(2), 296-315. https://doi.org/ $10.1177 / 0013916501332008$ 


\section{About the Authors}

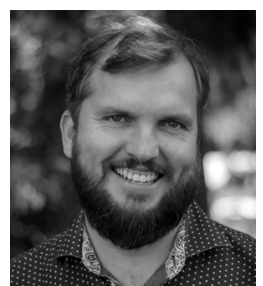

Mervyn Horgan is Associate Professor in the Department of Sociology and Anthropology at the University of Guelph (Canada), and Faculty Fellow of the Center for Cultural Sociology at Yale University. He has published widely on social theory, gentrification, stigmatization, strangers and public space. He is the Principal Investigator on the SSHRC-funded Sociable Cities Project.

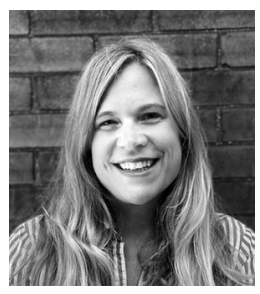

Saara Liinamaa is Assistant Professor in the Department of Sociology and Anthropology at the University of Guelph (Canada). As a cultural and urban sociologist, her research and publications examine practices of everyday life, with a particular interest in how individuals and organizations manage uncertainty and change. She is Co-Investigator on the Sociable Cities Project.

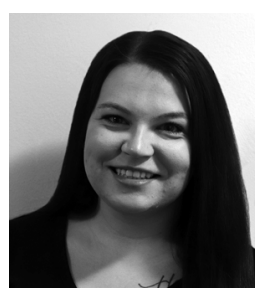

Amanda Dakin is a SSHRC-funded Sociology MA Student at the University of Guelph. She researches the regulation of public space and, in particular, how homeless persons are excluded from the public realm through the use of the outdoor built environment. She is a Research Assistant on the Sociable Cities Project.

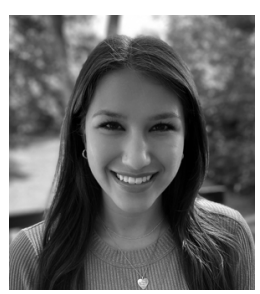

Sofia Meligrana is a Sociology MA Student at the University of Guelph. Her research interests include cultural (mis)appropriation, multiculturalism, ethnic minorities, and symbolic boundaries. Her MA research focuses on ethnic minority responses to cultural (mis)appropriation in Canada. She is a Research Assistant on the Sociable Cities Project.

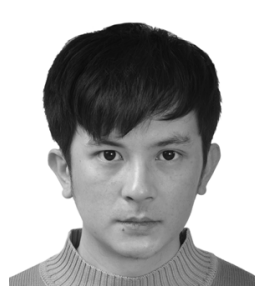

Meng Xu is a Sociology PhD Student at the University of Guelph. He holds a BA and an MA in Sociology from Minzu University of China. His areas of research interest include interactionism, public space, and consumption. He is a Research Assistant on the Sociable Cities Project. 